\title{
THE RITUAL HOARD FROM BARROW 1 OF THE BURIAL MOUND RESTUMOV II IN THE ROSTOV REGION
}

\author{
Mikhail V. Vlaskin \\ State Autonomous Institution of Culture of the Rostov Region "The Heritage of Don", \\ Rostov-on-Don, Russian Federation \\ Vyacheslav P. Glebov \\ Archaeological Research Bureau LLC, Rostov-on-Don, Russian Federation \\ Vyacheslav N. Kuzmin \\ State Autonomous Institution of Culture of the Rostov Region "The Heritage of Don", \\ Rostov-on-Don, Russian Federation
}

\begin{abstract}
The paper presents the ritual complex, which was found during the excavation of barrow 1 of the burial mound Restumov II on the left bank of the river Severskiy Donets in the Rostov region in 2001.

The complex consisted of a bronze cauldron with the following items: bits, rod-shaped cheek-pieces with flattened endings, phalerae with remnants of golden plating, three-bladed iron arrowheads with long petioles, a circular buckle with movable latch, a fragment of a mirror, spoon-shaped pendants - tips of belts, a fragment of an iron sleeve with a bronze ring. The complex was located in the eastern part of the barrow at a depth of about $1.5 \mathrm{~m}$.

The ritual hoard of the burial mound Restumov II can be dated back to the 2 nd -1 st centuries BC. Threebladed arrowheads with long faceted stalks allow specifying the date of the complex to the first half - the mid 2nd century BC.

The predominance of items peculiar of the Early Sarmatian culture of the Lower Don region in the complex allows the authors to suggest that the hoard was buried by Sarmatians. This can proved by the presence of spoonshaped pendants and arrows with long faceted petioles, which were used only by the Sarmatians in the Northern Black Sea region and neighboring regions and practically do not occur in any other ethno-cultural context.

However, the absence of such complexes in the ancestral home of the Early Sarmatians, in the Southern Trans-Urals and the Ural region, indicates that the tradition of ritual hoards is not Sarmatian in origin. Probably, Sarmatians borrowed the custom of burial of ritual hoards of horse equipment and weapons from their neighbours the Kuban meots, or from the cultures of Central Europe and the Northern Balkans.

Key words: ritual hoard, cauldron, horse harness and weapon, Early Sarmatian culture.

Citation. Vlaskin M.V., Glebov V.P., Kuzmin V.N., 2018. The Ritual Hoard from Barrow 1 of the Burial Mound Restumov II in the Rostov Region. The Lower Volga Archaeological Bulletin, vol. 17, no. 2, pp. 58-69. (in Russian). DOI: https://doi.org/10.15688/nav.jvolsu.2018.2.5

\section{РИТУАЛЬНЫЙ КЛАД ИЗ КУРГАНА 1 МОГИЛЬНИКА РЕСТУМОВ ІІ В РОСТОВСКОЙ ОБЛАСТИ}

\author{
Михаил Васильевич Власкин
}

ГАУК РО «Донское наследие», г. Ростов-на-Дону, Российская Федерация

\section{Вячеслав Петрович Глебов}

ООО «Археологическое научно-исследовательское бюро», г. Ростов-на-Дону, Российская Федерация 


\section{Вячеслав Николаевич Кузьмин}

ГАУК РО «Донское наследие», г. Ростов-на-Дону, Российская Федерация

Аннотация. В статье рассматривается ритуальный комплекс, найденный при раскопках кург. 1 могильника Рестумов II на левобережье р. Северский Донец в Ростовской области в 2001 году.

Комплекс представлял собой бронзовый котел с вещами внутри: удила, стержневидные псалии с уплощенными окончаниями, уздечные фалары с остатками золотой плакировки, железные трехлопастные наконечники стрел с длинными черешками, кольцевая пряжка с подвижным язычком, фрагмент зеркала, ложковидные подвески - наконечники ремней, фрагмент железной втулки с бронзовым кольцом. Комплекс находился в восточной поле кургана на глубине около 1,5 м.

Ритуальный клад из могильника Рестумова II может быть датирован в рамках II-I вв. до н.э. Трехлопастные наконечники стрел с длинными гранеными черешками позволяют сузить дату комплекса до первой половины - средней части II в. до н.э.

Преобладание в комплексе вещей, характерных для раннесарматской культуры Нижнего Подонья, позволяет утверждать, что клад был захоронен сарматами. Особенно показательны ложковидные подвески и стрелы с длинными гранеными черешками, которые в Северном Причерноморье и соседних регионах были в ходу только у сарматов и практически не встречаются в каком-либо ином этнокультурном контексте.

Однако отсутствие подобных комплексов на прародине ранних сарматов, в Южном Зауралье и Приуралье, указывает на то, что традиция ритуальных кладов по происхождению не сарматская. Вероятно, сарматы заимствовали обычай захоронения ритуальных кладов конского снаряжения и вооружения из внешней среды - у кубанских меотов или из культур Центральной Европы и Северных Балкан.

Ключевые слова: ритуальный клад, котел, конская упряжь и вооружение, раннесарматская культура.

Цитирование. Власкин М. В., Глебов В. П., Кузьмин В. Н. 2018. Ритуальный клад из кургана 1 могильника Рестумов II в Ростовской области // Нижневолжский археологический вестник. Т. 17, № 2. С. 58-69. DOI: https://doi.org/10.15688/nav.jvolsu.2018.2.5

В 2001 г. в связи со строительством магистрального нефтепровода «Суходольная Родионовская» в ряде районов Ростовской области проводились охранно-спасательные раскопки памятников археологии, оказавшихся в зоне строительных работ. На территории Каменского района Ростовской области археологические исследования велись совместным отрядом Ростовской областной инспекции по охране и эксплуатации памятников истории и культуры и Донским археологическим обществом. Наряду с другими памятниками в зоне строительства оказался курганный могильник Рестумов II [Кузьмин, 2002].

Курганный могильник Рестумов II находился на левобережье р. Северский Донец, на водоразделе между балками Рестумова и Терехов Буерак (правые притоки р. Глубокая), в 5,4 км к ЮЮВ от х. Кочетовка. Могильник состоял из шести насыпей, которые располагались компактной цепочкой, вытянутой по линии ССЗ - ЮЮВ (за исключением кург. 5) (рис. 1). Все курганы попадали в зону строительства нефтепровода, поэтому могильник исследовался полностью.

Курган 1, наиболее крупный в группе, находился в центральной части могильника.
Его высота составляла 3,6 м, диаметр - около 40 м, верхняя часть насыпи была задернована, полы распахивались. На вершине насыпи была установлена триангуляционная вышка. Курган был насыпан в эпоху бронзы, содержал 8 разновременных погребений и ритуальный комплекс (так называемый клад). Публикация этого ритуального клада и является задачей настоящей статьи.

Комплекс представлял собой бронзовый котел с вещами внутри: удила, псалии, фалары, наконечники стрел, пряжка, фрагмент зеркала, наконечники ремней, фрагмент железной втулки с бронзовым кольцом. Котел был сдвинут бульдозером, поэтому место расположения комплекса в насыпи устанавливается лишь приблизительно: в восточной поле кургана на глубине около 1,5 м от $R_{0}$ (вершины кургана).

\section{Описание вещчей:}

1. Котел бронзовый (рис. 2,1). Котел литой, тулово усеченно-сферической формы с сужением ко дну, край венчика резко отогнут наружу. В верхней части тулово опоясано рельефной веревочкой, узелок расположен под одной из ручек. Котел снабжен парой вертикальных ручек арочной формы с тремя выс- 
тупами-«кнопками». Под каждой из ручек, чуть ниже венчика, расположены кольцевые валики диаметром около $1 \mathrm{~cm}$ - следы глиняных пробок, закрывавших отверстия для вывода из литейной формы остатков расплавленной органической модели котла. Полый воронковидный поддон был изготовлен отдельно и соединен с котлом через отверстие в нижней части тулова при помощи литой пробки или пары заклепок с перемычкой (рис. 2,2). В древности котел был сплющен, тулово его в четырех местах пробито каким-то орудием (топором?), оставившим в стенках щелевидные отверстия размерами $1,5 \times 5$ см. Размеры котла: общая высота с поддоном и ручками - 37 см, диаметр тулова - приблизительно 34-35 см, толщина стенок котла и поддона $0,3-0,4$ см.

Котел принадлежит к типу VI варианту 2 подварианту А по типологии С.В. Демиденко. Котлы типа VI.2.А имели распространение главным образом в памятниках раннесарматской и среднесарматской культур, датируются в диапазоне второй половины II в. до н.э. - первой половины II в. н.э. [Демиденко, 2008, с. 18]. По мнению С.В. Демиденко, котел из Рестумова II относится к ранним образцам котлов типа VI и может быть датирован II-I вв. до н.э. ${ }^{1}$

2. Удила железные с кольцевыми окончаниями (рис. 3,3 ). Сохранилось лишь одно сильно коррозированное окончание звена удил, его размеры: $3,1 \times 2,4 \times 1,1 \mathrm{~cm}$.

3. Псалии железные стержневидные двухдырчатые с уплощенными окончаниями (рис. 3,2). Сохранились фрагменты стержня с парой отверстий в раскованной средней части и уплощенное ромбовидное окончание с остатками ажурной аппликации из золотой фольги. Возможно, противоположное окончание псалия также было уплощенное, но овальной формы - сохранился фрагмент, но без следов аппликации из золотой фольги (рис. 3,4).

4. Фалары железные с золотой плакировкой (рис. 3,1$)$ - два целых и фрагменты еще от трех или четырех. Фалары представляют собой слабовыпуклые дисковидные бляхи. На лицевой стороне некоторых сохранились остатки плакировки из золотой фольги в виде ажурных розеток(?) в центре и волнистой окан- товки по краю. На оборотной стороне блях имеется по одной петле, сделанной из узкой полоски железа. Диаметр двух целых блях - 5,6 см и 6,2 см, размеры единственной сохранившейся полностью петли - 3,0 × 0,6 × 0,3 cм.

Фалары из Рестумова II близки к типу 5 (варианты «a, b, с») уздечных фаларов по классификации В.И. Мордвинцевой, датирующихся широко - в рамках III в. до н.э. - II в. н.э. [Мордвинцева, 1998, с. 53].

5. Фрагмент бронзового зеркала (рис. 3,7). Зеркало представляло собой диск со слабовыраженным валиком. Размеры: реконструируемый диаметр зеркала $-8,3$ см, толщина диска - 0,15 см, ширина валика $-1,1$ см.

Очевидно, что данный экземпляр относится к зеркалам в виде небольшого плоского диска без ручки (тип VI по A.M. Хазанову, тип 1.01 по А.С. Скрипкину). У большинства зеркал этого типа край диска скошен или приострен, в редких случаях - слегка утолщен или оформлен в виде едва намеченного валика. Пик популярности этого типа зеркал приходится на I в. до н.э. - первую половину I в. н.э. [Скрипкин, 1990, рис. 44; Глухов, 2005, с. 4546]. Однако такие зеркала достаточно хорошо представлены и в памятниках раннесарматской культуры II в. до н.э. (Подгорненский IV, кург. 6, погр. 8; Подгорненский V, кург. 1, погр. 8; Подгорненский VI, кург. 1, погр. 8; Кулешовка, кург. 1, погр. 17, погр. 29А, погр. 29Б; Поляков, кург. 5 , погр. 3 , и др.), а эпизодически встречаются и в комплексах более раннего времени (Кащеевка, кург. 1, погр. 1).

6. Железные ложковидные подвески - наконечники ремней, 6 экз. (рис. 3,8). Все наконечники однотипные-уплощенное окончание скруглено, верхняя часть свернута во втулку. По размерам выделяется 2 варианта:

- 4 экз. небольших размеров: длина $3,2-$ 3,6 см, ширина ложечек 1,2-1,6 см (рис. 3,8a); - 2 экз. более крупные, сохранились не полностью - у обоих утрачены втулки. Длина сохранившейся части наконечников 7,0 см и 5,5 см, ширина ложечек соответственно $1,3 \mathrm{~cm}$ и 1,4 см (рис. 3,86$)$.

Ложковидные наконечники поясных ремней, изготовленные из разного материала (бронза, железо, кость), достаточно часто встречаются в погребениях раннесарматской культуры (Алитуб, кург. 3, погр. 20; Сухо- 
Дюдеревский II, кург. 1, погр. 12; Балабинский II, кург. 4, погр. 5; Попов, кург. 58/26, погр. 9; Первомайский VII, кург. 50, погр. 4; Верхнее Погромное, кург. 6, погр. 8; Калиновский, кург. 8, погр. 40; Быково, кург. 11, погр. 6; Покровка I, кург. 3, погр. 1, кург. 12, погр. 1; Старые Киишки, кург. 13, погр. 4, погр. 13 и др.). Подобные подвески известны и в комплексах среднесарматского времени (Пороги, кург. 2, погр. 1; Дачи, кург. 1, тайник; Яшкуль, группа 37, кург. 1 погр. 1; Первомайский VII, кург. 14, погр. 3; Жутовский, кург. 28, погр. 1; Октябрьский V, кург. 1 , погр. 1; Косика, погр. 1 и др.). Ложковидные подвески среднесарматского времени, в отличие от раннесарматских, обычно сделаны из золота, зачастую украшены вставками из эмали, стекла, перламутра, бирюзы. Иногда им приданы зооморфные черты (Дачи).

Традиция украшения ремней ложковидными подвесками, бесспорно, происходит с востока, где подобные наконечники известны в культурах разных регионов: в Забайкалье, Западной Сибири (Тува, Средний Енисей, Алтай), лесостепном Южном Зауралье, Средней Азии. В Сарматию ложковидные наконечники ремней попадают во II в. до н.э. с последней миграционной волной носителей раннесарматской культуры, вместе с целой серией других инноваций восточного облика - длинные мечи с небольшими ромбическими перекрестьями и штыревидными рукоятями без навершия, мечи с кольцевыми навершиями, миниатюрные бронзовые модельки котлов и горитов, бронзовые ажурные пряжки с зооморфными изображениями, гагатовые пряжки, зеркала «бактрийского» типа и др. [Скрипкин, 2000, с. 17-26; 2005, с. 181-184; Минеева, Скрипкин, 2005, с. 52-53].

Детали поясной гарнитуры (поясные кольца, пряжки и др.) в составе ритуальных кладов нередки [Зайцев, 2008, с. 149], но ложковидные наконечники встречены только в Рестумове. Впрочем, в рестумовском кладе ложковидные наконечники могли относиться не к поясному набору, а к конской упряжи такие случаи известны, правда, уже в среднесарматское время (Яшкуль, Жутово).

7. Железные трехлопастные наконечники стрел с длинными черешками (рис. 2,3). Наконечники в большинстве случаев фрагментированы, некоторые черешки и головки согнуты. Точное количество наконечников не определяется в силу фрагментированности и плохой сохранности, но, вероятно, их было не менее 10 штук. Насколько можно судить по уцелевшим экземплярам, в наборе представлены наконечники нескольких вариантов по размерам и пропорциям головки:

- наконечники с головками низких пропорций - с широким основанием (1,2-1,6 см) и невысокой сводчатой или треугольной головкой (1,9-2,4 см) - 4 шт. (рис. 2,3a);

- наконечник с головкой средних пропорций: ширина основания - 0,9 см, высота головки $-2,4$ см $(2,36)$;

- наконечник с головкой высоких пропорций: ширина основания $-0,8$ см, высота головки - 3,2 см $(2,38)$.

Длина сохранившихся черешков-5,3-6,2 cм. Часть черешков четырехгранные (подквадратные или ромбические в сечении), часть - округлые в сечении.

Наконечники стрел с длинными черешками традиционно считаются наиболее ранними среди черешковых трехлопастных наконечников раннесарматской культуры [Мошкова, 1963, с. 32; Хазанов, 1971, с. 36-37; Скрипкин, 1990, с. 141]. Ранним признаком можно считать и четырехгранность черешков стрел - в Нижнем Подонье все находки наконечников стрел с длинными гранеными черешками относятся к раннему горизонту памятников нижнедонской раннесарматской культуры, датирующемуся началом и средней частью II в. до н.э. [Глебов, 2007, с. 91-92; 2010, c. 15-16]. В более позднем контексте такие наконечники пока не известны.

8. Железная кольцевая пряжка с подвижным язычком (рис. 3,6). Рамка и язычок в сечении округлые, соединены шарнирным способом. Размеры рамки $-3,5 \times 3,4$ см, толщина - 0,6 см.

Высказанное когда-то М.Г. Мошковой утверждение, что в последних веках до нашей эры у сарматов господствовали пряжки с неподвижным язычком, а кольцевые пряжки с подвижным язычком получили распространение только после рубежа эр [Мошкова, 1963, с. 40], нуждается в корректировке. Кольцевые пряжки с подвижным язычком достаточно хорошо представлены в материалах нижнедонской раннесарматской культуры II-I вв. до н.э., 
в том числе и в комплексах ее раннего этапа (Подгорненский V, кург. 1, погр. 1, кург. 6, погр. 2; Подгорненский VI, кург. 1, погр. 8; Ясырев I, кург. 8, погр. 19; Веселый, кург. 2, погр. 6; Койсуг, кург. 5, погр. 1 и др.).

Наша пряжка могла относиться как к поясу, так и к конской упряжи. Случаи использования пряжек с подвижными язычками для застегивания ремней узды и подпруги не являются редкостью [Симоненко, 2010, рис. 152, 154, 156, 188].

\section{9. Фрагмент железной втулки с} бронзовым кольцом (рис. 3,5). Кольцо сделано из округлого в сечении прута толщиной 0,4 см, его диаметр - 2,8 см. Внутри кольца зажат фрагмент железной цилиндрической втулки, длина сохранившейся части 1,8 см.

Обращает на себя внимание то, что большая часть предметов из комплекса фрагментирована или деформирована. Особенно показателен характер повреждений наконечников стрел и черешков - многие из них не только фрагментированы, но и согнуты. Это трудно списать на обычай ритуальной порчи - наконечники стрел в раннесарматское время не подвергалась ритуальной порче, в отличие от зеркал, мечей, котлов и других предметов [Глебов, 2011, с. 36]. Следует предположить, что вещи были помещены в еще целый котел и получили повреждения в результате сплющивания котла и ударов по его тулову.

Исходя из датировки большинства вещей, широкая дата ритуального клада в Рестумове II может быть определена в рамках II-I вв. до н.э. Трехлопастные наконечники стрел с длинными четырехгранными черешками позволяют сузить дату комплекса до первой половины - средней части II в. до н.э.

Подобные комплексы получили в литературе известность как «ритуальные клады», «вотивные клады», «странные комплексы», «жертвенно-поминальные комплексы». Количество их в Северном Причерноморье и соседних регионах по некоторым оценкам составляет около 50 [Зайцев, 2012, с. 68, карта 1; Полин, 2014, с. 641]. Ритуальные клады представляют собой наборы предметов, захороненные чаще всего в насыпях больших курганов, реже - в естественных возвышенностях (возможно, с возведением собствен- ной небольшой насыпи). Известно несколько случаев находок таких кладов на склонах балок [Глебов, 2016, с. 145-161]. Вещи обычно компактно сгруппированы, зачастую сложены в какое-то вместилище - котел, ситулу, шлем. Состав кладов, как правило, достаточно единообразен: детали конской упряжи (фалары, налобники, удила с псалиями и пр.), предметы вооружения (наконечники стрел и копий, мечи, шлемы, панцири). Из прочих категорий вещей, часто присутствующих в кладах, можно назвать разнообразную посуду (металлическую, стеклянную, керамическую), детали поясной гарнитуры. Кроме того, единично в их составе встречаются самые разнообразные предметы: фибулы, бронзовые светильники, зеркала, оселки и пр.

Как и большинство «странных комплексов», ритуальный клад из Рестумова II захоронен в крупном кургане, все вещи помещены в котел, состав комплекса можно назвать стандартным: он содержит два главных и почти обязательных атрибута кладов - детали конской упряжи (уздечный набор: удила, псалии и фалары оголовья) и предметы вооружения (черешковые наконечники стрел). Заметим, что стрелы в ритуальных кладах встречаются достаточно часто, но почти во всех случаях это не черешковые, а втульчатые наконечники стрел [Савельев, 2010, c. 179-180]. Судя по иллюстрациям, черешковые наконечники, наряду со втульчатыми, присутствуют в Гордашевском кладе, хотя в описании этого комплекса упомянуты только втульчатые [Полин, Карнаух, 2012, с. 139140 , рис. $6,8-17]$.

Из необычных для кладов вещей в комплексе из Рестумова следует отметить, прежде всего, ложковидные подвески - наконечники ремней. Ложковидные наконечники в составе ритуального клада встречены впервые, хотя детали конской упряжи или поясной гарнитуры (в каком именно качестве использовались ложковидные подвески, в нашем случае неясно) в «странных комплексах» не являются редкостью. Интересен и фрагмент зеркала - предмет, совершенно не характерный для ритуальных кладов. Известна только одна находка зеркала в составе ритуального клада - в кург. 2 могильника Острый, но там оно использовалось как деталь нагрудника кон- 
ской сбруи [Зарайская и др., 2004, с. 137-138, 142 , рис. 1,5$]$.

Однако, несмотря на свою типичность, рестумовский клад весьма интересен в свете проблемы этнокультурной принадлежности ритуальных кладов. Как известно, ареал распространения ритуальных кладов III-I вв. до н.э. очень широк - Северное Причерноморье, Прикубанье, Нижнее и Среднее Подонье, Поволжье - и не совпадает с границами ни одной из археологических культур этого времени. В литературе существуют гипотезы о сарматской, позднескифской, кельтской (латенской) принадлежности ритуальных кладов, есть также мнения, что обычай захоронения кладов представлял собой надкультурное явление, присущее как кочевникам западных областей Сарматии, так и части поздних скифов. Краткое изложение основных версий приведено в статье Ю.П. Зайцева [2012, с. 67-71]. Не вдаваясь здесь в дискуссию об атрибуции ритуальных кладов на всей территории их распространения, отметим, что большинство кладов в степной части доно-волжского и кубанского регионов, очевидно, оставлены кочевникамисарматами. В степном Прикубанье, Подонье и Поволжье источниками в это время засвидетельствовано только сарматское население. Сколько-нибудь заметное скифское или кельтское присутствие в последних веках до н.э. здесь не фиксируется.

Этот тезис убедительно подтверждается кладом из могильника Рестумов II, который почти полностью состоит из вещей, свойственных раннесарматской культуре II-I вв. до н.э.: котел, наконечники стрел с длинными гранеными черешками, ложковидные наконечники ремней, зеркало. Особенно показательны ложковидные подвески и стрелы с длинными гранеными черешками, которые в Северном Причерноморье и соседних регионах были в ходу только у сарматов и практически не встречаются в каком-либо ином этнокультурном контексте.

Таким образом, состав ритуального клада из Рестумова II не оставляет сомнений в том, что этот комплекс мог быть оставлен только сарматами. Вещи, характерные для раннесарматской культуры, встречены и в других кладах восточной группы - мечи с серповидными навершиями из Веселого и
Острого, котел и зооморфный крючок из Качалинской и др.

Вместе с тем очевидно, что традиция ритуальных кладов по происхождению не сарматская - на прародине ранних сарматов, в Южном Зауралье и Приуралье, пока не обнаружено ни одного подобного комплекса. Распространение этого обычая у кочевников западных регионов Сарматии, видимо, было результатом заимствования его сарматами из внешней среды.

У кого же сарматы могли заимствовать обычай сокрытия кладов конского снаряжения и вооружения? В настоящее время в литературе нет единства мнений по этому поводу. А.В. Симоненко считает, что обычай захоронения ритуальных кладов возник в сирако-меотской среде Северо-Западного Предкавказья, не уточняя истоков этой традиции [Симоненко, 2001, с. 94-96; 2005, с. 258-259; 2018, с. 35]. Б.А. Раев выводит традицию ритуальных кладов у сарматов от кубанских жертвенных комплексов. Этот вывод был сделан им на основании находки в жертвенном комплексе из грунтового могильника городища Новолабинское IV трех налобников с крючком, аналогичных найденным в кладах западной группы ${ }^{2}$.

Ю.П. Зайцев в одной из своих работ высказывал мнение, что истоки традиции ритуальных кладов оружия и конского снаряжения следует искать в культурах Центральной Европы и Северных Балкан, где похожий обычай существует с эпохи гальштатта [Зайцев, 2007, с. 266]. Оттуда в последних веках до нашей эры обряд сокрытия кладов распространился в Северо-Западное Причерноморье и далее на восток.

Наличие подобных ритуальных комплексов на территории современных Болгарии, Венгрии, Румынии отмечают и другие исследователи [Мордвинцева, 2013, с. 154; Полин, 2014, c. 641].

Таким образом, вопрос происхождения традиции ритуальных кладов конского снаряжения и вооружения сегодня остается дискуссионным. Воздерживаясь от каких-либо окончательных выводов, подчеркнем лишь несомненную, на наш взгляд, сарматскую принадлежность комплекса из кург. 1 могильника Рестумов II. 
M.V. Vlaskin, V.P. Glebov, V.N. Kuzmin. The Ritual Hoard from Barrow 1 of the Burial Mound Restumov II

\section{ИЛЛЮСТРАЦИИ}
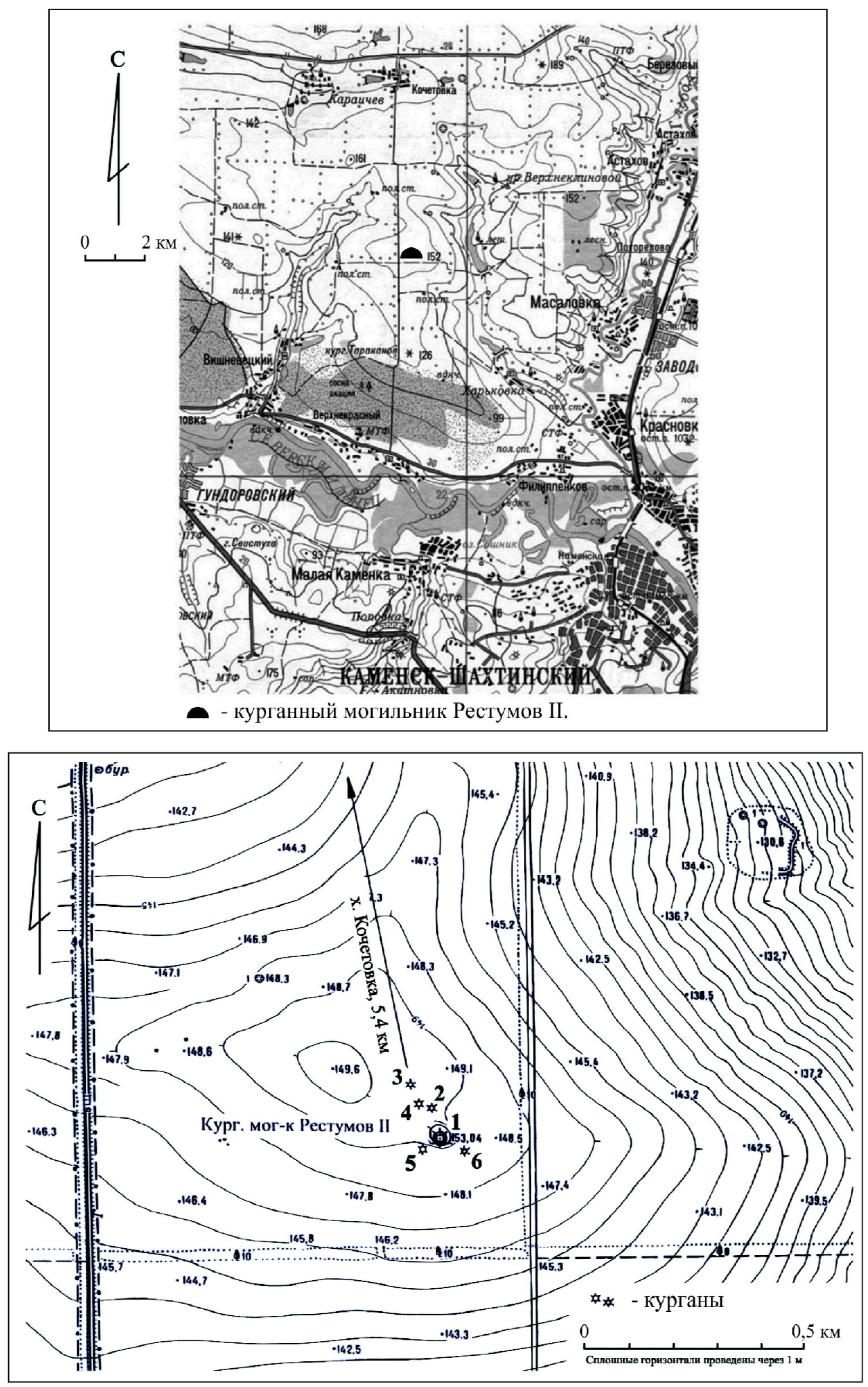

Рис. 1. Расположение и план курганного могильника Рестумов II

Fig. 1. Location and plan of the burial mound Restumov II 


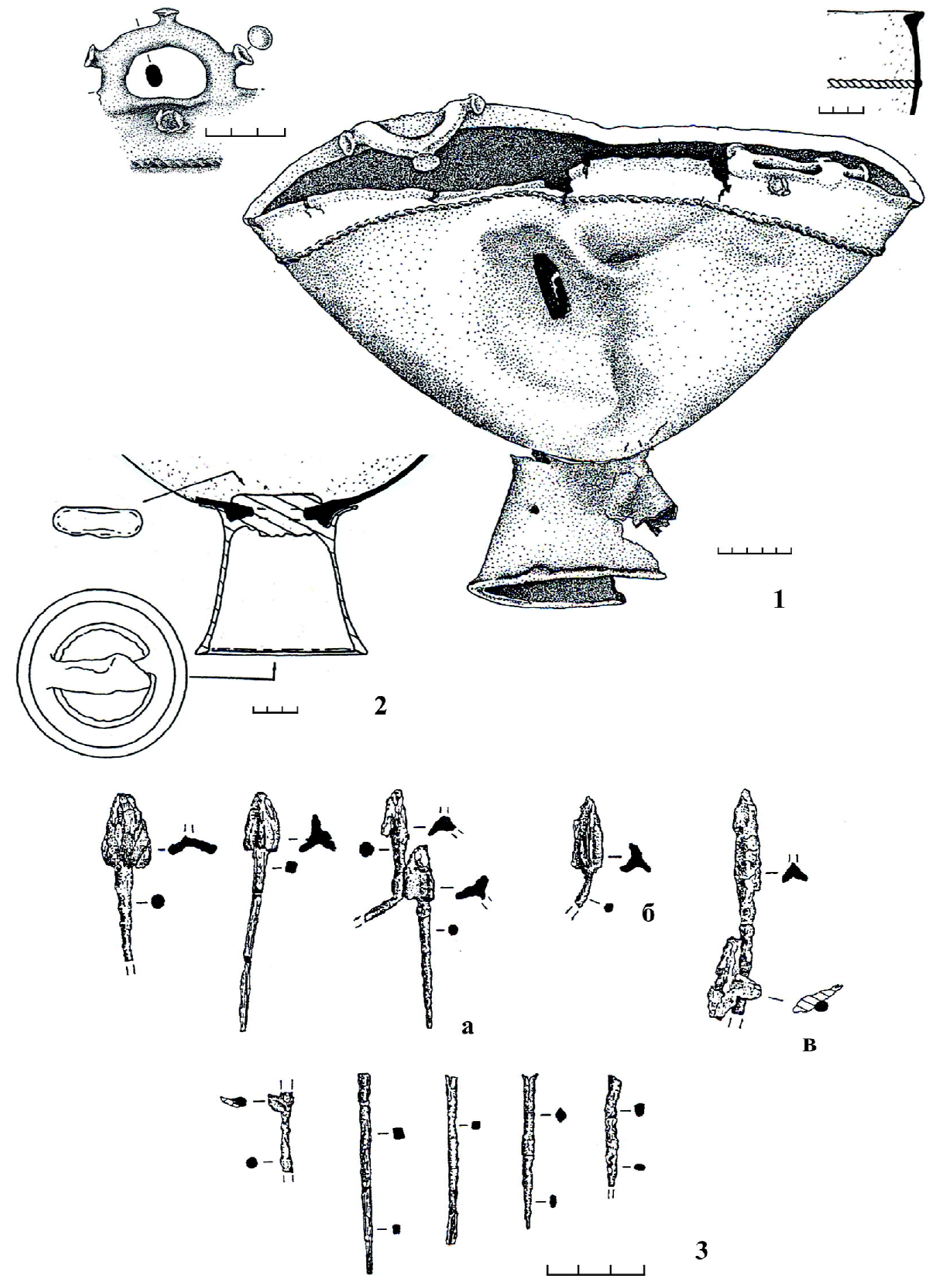

Рис. 2. Ритуальный клад из кург. 1 могильника Рестумов II:

1 - бронзовый котел; 2 - схема крепления ножки к тулову котла;

3 - железные черешковые наконечники стрел и фрагменты черешков

Fig. 2. Ritual hoard from barrow 1 of the burial mound Restumov II: 1 - bronze cauldron; 2 - scheme of fastening the legs to the body of the cauldron; 3 - iron petiolate arrowheads and fragments of petioles 

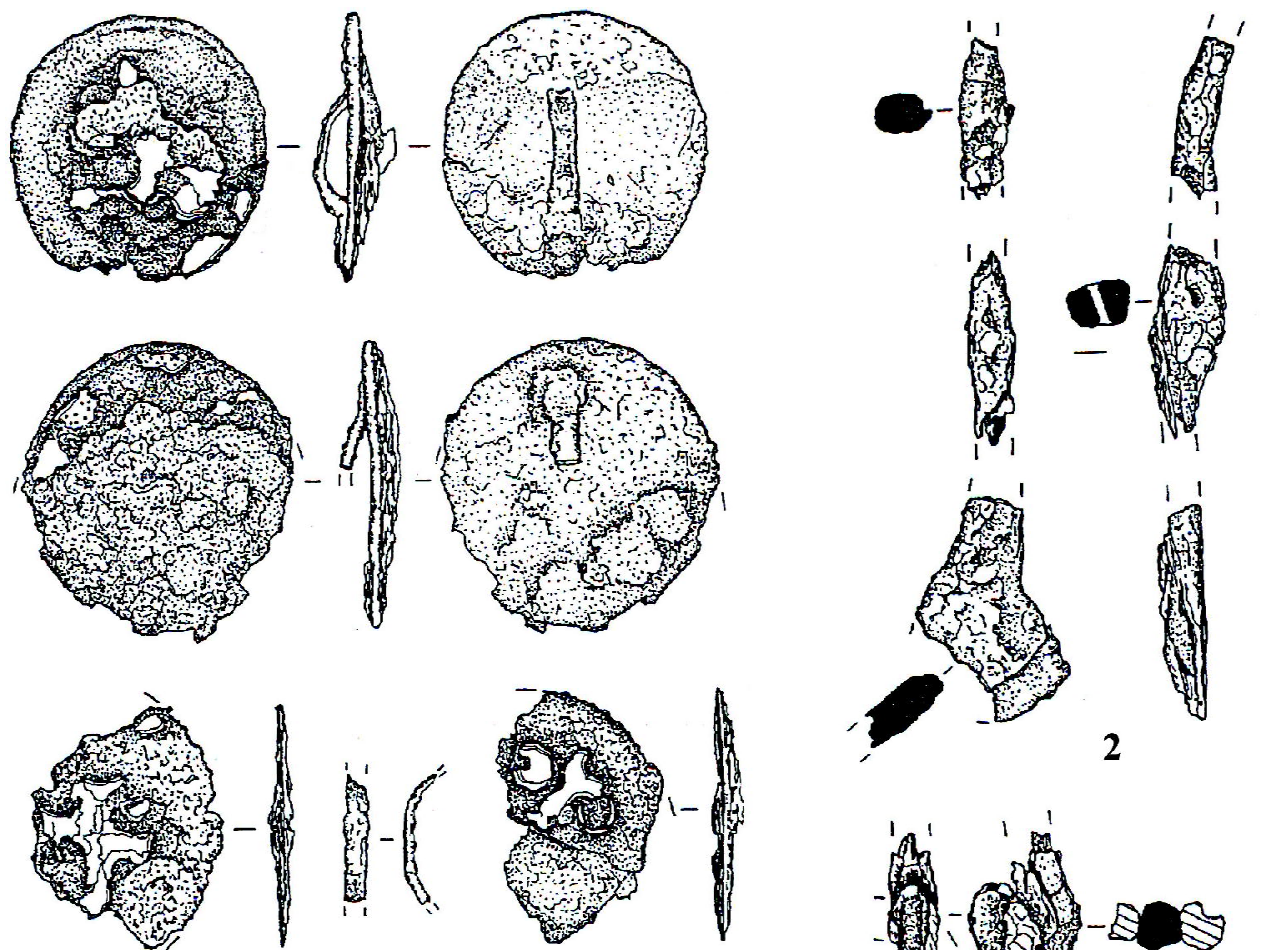

1
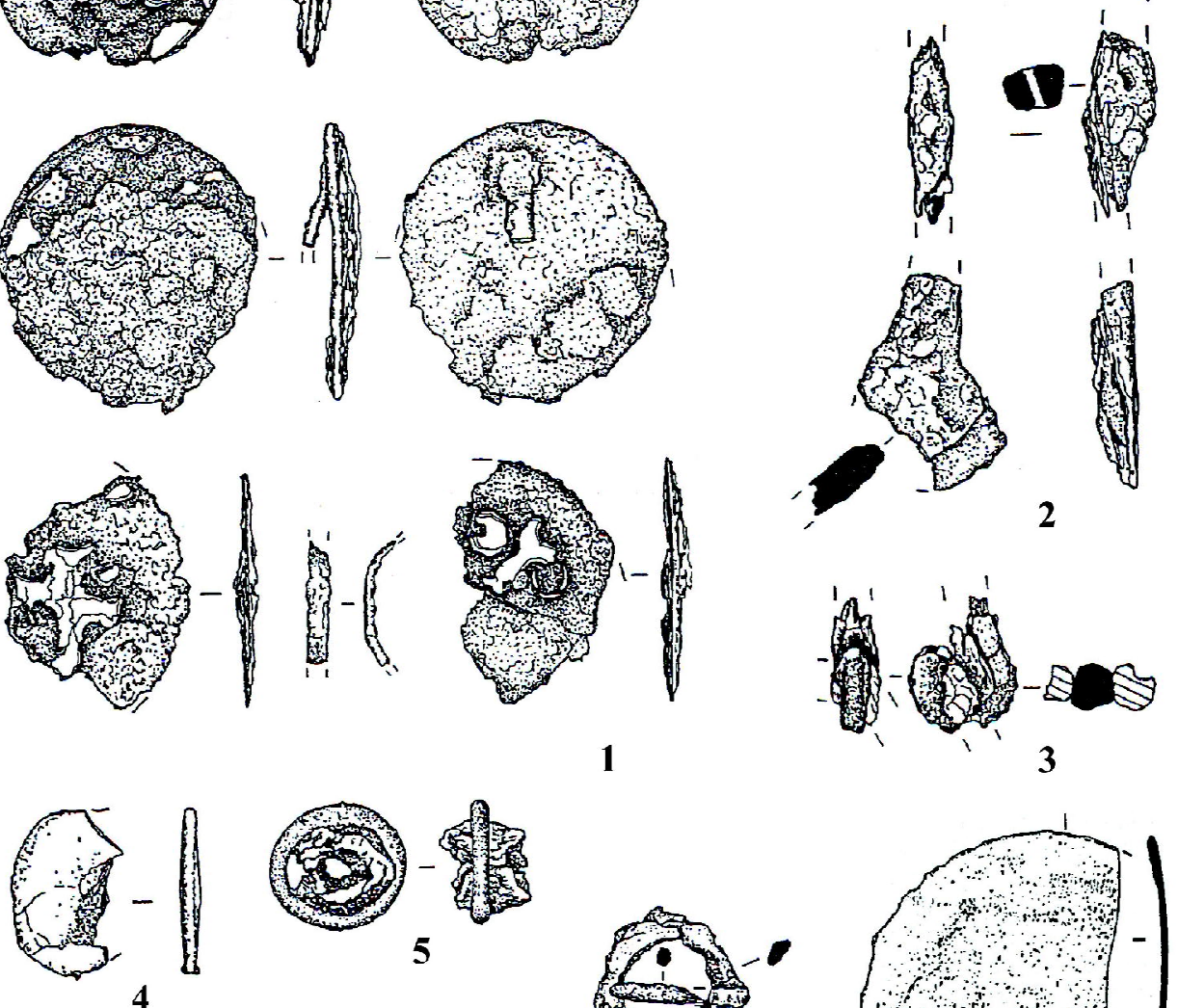

4

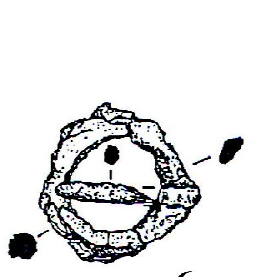

$0-8$

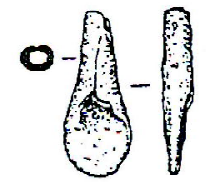

6
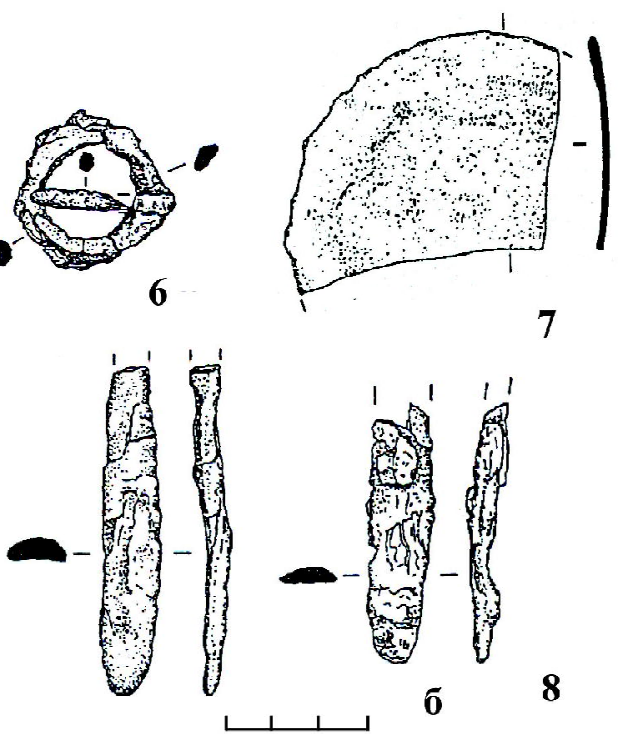

Рис. 3. Ритуальный клад из кург. 1 могильника Рестумов II:

1 - железные фалары с золотой плакировкой; 2 - железный псалий; 3 - фрагменты железных удил; 4 - железный предмет (окончание псалия?); 5 - фрагмент железной втулки с бронзовым кольцом; 6 - железная пряжка; 7 - фрагмент бронзового зеркала; 8 - железные наконечники ремней

Fig. 3. Ritual hoard from barrow 1 of the burial mound Restumov II:

1 - iron phalerae with golden plating; 2 - iron cheek-piece; 3 - fragments of iron bits; 4 - iron item (ending of a cheek-piece?); 5 - fragment of an iron sleeve with a bronze ring; 6 - iron buckle; 7 - fragment of a bronze mirror; 8 - iron tips of belts 


\section{ПРИМЕЧАНИЯ}

${ }^{1}$ Авторы выражают благодарность С.В. Демиденко за консультацию по поводу данного котла.

2 Доклад Б.А. Раева «У истоков “странных комплексов": погребение 71 Новолабинского могильника» на Международном научном семинаре «История и культура сарматов: традиционный и междисциплинарный подход» в Центре изучения истории и культуры сарматов Волгоградского госуниверситета (3-5 декабря 2015 год).

\section{СПИСОК ЛИТЕРАТУРЫ}

Глебов В. П., 2007. Вооружение и военное дело кочевников Нижнего Подонья раннесарматского времени // Вооружение сарматов: региональная типология и хронология : докл. к VI Междунар. конф. «Проблемы сарматской археологии и истории». Челябинск : Издво ЮУрГУ. С. 88-98.

Глебов В. П., 2010. Раннесарматская культура Нижнего Подонья II-I вв. до н.э. : автореф. дис. ... канд. ист. наук. М. 26 с.

Глебов В. П., 2011. Погребальная обрядность раннесарматской культуры Нижнего Подонья II-І вв. до н.э. // Погребальный обряд ранних кочевников Евразии : материалы VII Междунар. науч. конф. «Проблемы сарматской археологии и истории». Ростов-н/Д : Изд-во ЮНЦРАН. C. $34-48$.

Глебов В. П., 2016. О вариантах обряда захоронения «ритуальных кладов» III-І вв. до н.э. // Stratum plus. № 3. C. 145-161.

Глухов А. А., 2005. Сарматы междуречья Волги и Дона в I- первой половине II в. н.э. Волгоград : Волгоградское научное издательство. 240 с.

Демиденко С. В., 2008. Бронзовые котлы древних племен Нижнего Поволжья и Южного Приуралья (V в. до н.э. - III в. н.э.). М. : Изд-во ЛКИ. $303 \mathrm{c.}$

Зайцев Ю. П., 2007. Комплекс из Гэвани (к проблеме хронологии III в. до н.э.) // Боспорский феномен. Сакральный смысл региона, памятников, находок : материалы Междунар. науч. конф. Ч. 2. СПб : Изд-во Гос. Эрмитажа. С. 258-268.

Зайцев Ю. П., 2008. Вотивные клады Северо-Западного Причерноморья III-I вв. до н.э. Хронология и культурная принадлежность // Древнее Причерноморье. Вып. VIII. Одесса : ФЛП «Фридман А.С.». С. 146-152.

Зайцев Ю. П., 2012. Северное Причерноморье в III-II вв. до н.э.: ритуальные клады и археологические культуры (постановка проблемы) // Древности Северного Причерномо- рья III-II вв. до н.э. Тирасполь : Изд-во ПГУ. C. $67-72$.

Зарайская Н. П., Привалов А. И., Шепко Л. Г., 2004. Курган раннего железного века у пос. Острый // Донецкий археологический сборник. Вып. 11. Донецк : Изд-во Донецкого ГУ. C. $130-144$.

Кузьмин В. Н., 2002. Отчет об аварийно-спасательных раскопках курганных могильников Малая Каменка VI, Рестумов I, Рестумов II и Малая Каменка IX в Каменском районе Ростовской области в 2001 году// Архив РОМК. Ф-Р. Д. 252.

Минеева О. И., Скрипкин А. С., 2005. О происхождении и времени появления одного из типов бронзовых зеркал у сарматов // Нижневолжский археологический вестник. Вып. 7. С. 51-56.

Мордвинцева В. И., 1998. Классификация фаларов конской упряжи 3 в. до н.э. - начала 2 в. н.э. и типы парадного конского снаряжения // Античная цивилизация и варварский мир (Материалы 6-го археологического семинара). Краснодар. Ч. 1. С. 51-67.

Мордвинцева В. И., 2013. Комплекс предметов из Булаховки и «ритуальные клады» Северного Причерноморья III-I вв. до н.э. // Проблемы истории, филологии, культуры. № 2 (40). C. $144-156$.

Мошкова М. Г., 1963. Памятники прохоровской культуры. М. : Изд-во АН СССР. 56 с.

Полин С. В., 2014. Скифский Золотобалковский курганный могильник V-IV вв. до н.э. на Херсонщине. Киев : Изд. «Олег Филюк». 776 с.

Полин С. В., Карнаух Е. Г., 2012. Гордашевский «клад» // Древности Северного Причерноморья III-ІІ вв. до н.э. Тирасполь : Изд-во ПГУ. C. 134-144.

Савельев О. К., 2010. Оружие дальнего боя из «странных комплексов» // Stratum plus. № 3. C. $175-184$.

Симоненко А. В., 2001. Погребение у с. Чистенькое и «странные» комплексы последних веков до н.э. // Нижневолжский археологический вестник. Вып. 4. С. 92-106.

Симоненко А. В., 2005. Тираспольские курганы, «странные комплексы» и сираки на Днестре // Четвертая кубанская археологическая конференция. Тезисы и доклады. Краснодар. C. $255-260$.

Симоненко А. В., 2010. Сарматские всадники Северного Причерноморья. СПб : Фак-т филологии и искусств СПбГУ; Нестор-История. 328 с.

Симоненко А. В., 2018. О сарматском завоевании Скифии // Нижневолжский археологический вестник. Т. 17, № 1. С. 27-49.

Скрипкин А. С., 1990. Азиатская Сарматия. Проблемы хронологии и ее исторический ас- 
пект. Саратов : Изд-во Саратовского ун-та, $1990.300 \mathrm{c}$.

Скрипкин А. С., 2000. Новые аспекты в изучении истории материальной культуры сарматов // Нижневолжский археологический вестник. Вып. 3. С. 17-40.

Скрипкин А. С., 2005. Сарматские мечи с кольцевидным навершием // II Городцовские чтения : материалы науч. конф. М. : Изд-во ГИМ. C. 171-185.

Хазанов А. М., 1971. Очерки военного дела сарматов. М. : Изд-во «Наука». 172 с.

\section{REFERENCES}

Glebov V.P., 2007. Arms and Warfare of the Nomads of the Lower Don Region in the Early Sarmatian Time. Vooruzhenie sarmatov. Regionalnaya tipologiya $i$ khronologiya: doklady $k$ VI mezhdunarodnoy konferentsii "Problemy sarmatskoy arkheologii $i$ istorii". Chelyabinsk, Izd-vo YuUrGU, pp. 88-98. (in Russian).

Glebov V.P., 2010. Early Sarmatian Culture of the Lower Don of the $2^{\text {nd }}-1^{\text {st }}$ Centuries BC. Cand. hist. sci. abs. diss. Moscow. 26 p. (in Russian).

Glebov V.P., 2011. Funeral Rite of the Early Sarmatian Culture of the Lower Don Region of the $2^{\text {nd }}$ $1^{\text {st }}$ Centuries BC. Pogrebalnyy obryad rannikh kochevnikov Evrazii: materialy VII Mezhdunarodnoy nauchnoy konferentsii "Problemy sarmatskoy arkheologii i istorii". Rostov-on-Don, Izd-vo YuNTs RAN, pp. 34-48. (in Russian).

Glebov V.P., 2016. About Variants of the Funeral Practice of Ritual Hoards of $3^{\text {rd }}-1^{\text {st }}$ Centuries BC. Stratum plus, no. 3, pp. 145-161. (in Russian).

Glukhov A.A., 2005. The Sarmatians between the Rivers Volga and Don in the $1^{\text {st }}$ - First Half of $2^{\text {nd }}$ Century $A D$. Volgograd, Volgogradskoe nauchnoe izd-vo. 240 p. (in Russian).

Demidenko S.V., 2008. Bronze cauldrons of ancient tribes of the Lower Volga and Southern Urals (the $5^{\text {th }}$ century $B C-3^{\text {rd }}$ century $\left.A D\right)$. Moscow, Izd-vo LKI. 303 p. (in Russian).

Zaytsev Yu.P., 2007. Complex of Gavani (on the Problem of Chronology of the $3^{\mathrm{d}}$ century $\left.\mathrm{BC}\right)$. The Phenomenon of Bosporan Kingdom: the Sacred Meaning of the Region, Sites and Finds. Saint Petersburg, The State Hermitage Publ., pp. 258268. (in Russian).

Zaytsev Yu.P., 2008. Votive Treasures of the NorthWestern Pontic Region in the $3^{\mathrm{d}}-1^{\text {st }}$ Centuries BC. Chronology and Cultural Affiliation. Drevnee Prichernomorye. iss. VIII. Odessa, Fridman A.S. Publ., pp. 146-152. (in Russian).
Zaytsev Yu.P., 2012. The Northern Black Sea Region in the $3^{\text {rd }}-2^{\text {nd }}$ Centuries BC: Ritual Treasures and Archaeological Cultures (Problem Statement). Drevnosti Severnogo Prichernomorya III-II vv. do n.e. Tiraspol, Izd-vo PGU,pp. 67-72. (in Russian).

Zarayskaya N.P., Privalov A.I., Shepko L.G., 2004. Barrow of the Early Iron Age in the Village Ostryy. Donetskiy arkheologicheskiy sbornik, iss. 11. Donetsk, Izd-vo DGU, pp. 130-144. (in Russian).

Kuzmin V.N., 2002. Report on Rescue Excavations of the Burial Mounds Malaya Kamenka VI, Restumov I, Restumov II and Malaya Kamenka IX in the Kamensky District of the Rostov Region in 2001. Arkhiv ROMK, F-R, d. 252. (in Russian).

Mineeva O.I., Skripkin A.S., 2005. About Origin and Time of Occurrence of One of the Types of Bronze Mirrors in the Sarmatian Culture. The Lower Volga Archaeological Bulletin, iss. 7, pp. 51-56. (in Russian).

Mordvintseva V.I., 1998. Classification of Phalerae of Horse Harness of the $3^{\text {rd }}$ Century BC the Beginning of the $2^{\text {nd }}$ Century AD and Types of Ceremonial Horse Equipment. Antichnaya tsivilizaciya $i$ varvarskiy mir (Materialy 6-go arkheologicheskogo seminara). Part 1. Krasnodar, pp. 51-67. (in Russian).

Mordvintseva V. I., 2013. A Complex of Objects from the Bulakhovka and Ritual Hoards of the Northern Black Sea Region in the $3^{\text {rd }}-$ $1^{\text {st }}$ Centuries BC. Journal of historical, philological and cultural studies, no. 2 (40), pp. 144-156. (in Russian).

Moshkova M.G., 1963. The Monuments of Prokhorovka Culture. Moscow, Izd-vo AN SSSR. 56 p. (in Russian).

Polin S.V. 2014. The Scythian Barrow Necropolis Zolotaya Balka of the $5^{\text {th }}-4^{\text {th }}$ Centuries BC in the Kherson Region. Kiev, Oleg Filyuk Publ. 776 p. (in Russian).

Polin S.V., Karnaukh E.G., 2012. Gordashevsky "hoard". Drevnosti Severnogo Prichernomorya III-II vv. do n.e. Tiraspol, Izd-vo PGU, pp. 134-144. (in Russian).

Savelyev O.K., 2010. Ranged Weapons from the "Odd Complexes”. Stratum plus, no. 3, pp. 175-184. (in Russian).

Simonenko A.V., 2001. The Burial at the Chistenkoe Village and "Strange Complexes" of the Last Centuries BC. The Lower Volga Archaeological Bulletin, iss. 4, pp. 92-106. (in Russian).

Simonenko A.V., 2005. Tiraspol Barrows, "Strange Complexes" and the Siraki on the Dniester. Chetvertaya kubanskaya arkheologicheskaya 
konferentsiya. Tezisy $i$ doklady. Krasnodar, pp. 255-260. (in Russian).

Simonenko A.V., 2010. Sarmatian Riders of the North Pontic Region. Saint Petersburg, Fakultet filologii i iskusstv SPbGU; Nestor-Istoriya Publ. 328 p. (in Russian).

Simonenko A.V., 2018. On the Sarmatian Conquest of Scythia. The Lower Volga Archaeological Bulletin, vol. 17, no. 1, pp. 27-49. (in Russian). Skripkin A.S., 1990. Asian Sarmatia. Problems of Chronology and Its Historical Aspect. Saratov, Izd-vo SGU. 299 p. (in Russian).
Skripkin A.S., 2000. New Aspects in the Investigation of the History of Sarmatian Material Culture. The Lower Volga Archaeological Bulletin, iss. 3, pp. 17-40. (in Russian).

Skripkin A.S., 2005. Sarmatian Swords with RingShaped Pommel. II Gorodtsovskie chteniya: materialy nauchnoy konferencii. Moscow, Izd-vo GIM, pp. 171-185. (in Russian).

Khazanov A.M., 1971. Essays on Warfare of the Sarmatians. Moscow, Nauka Publ. 172 p. (in Russian).

\section{Information about the Authors}

Mikhail V. Vlaskin, Director of State Autonomous Institution of Culture of the Rostov Region "The Heritage of Don", Nizhnebulvarnaya St., 29, 344022 Rostov-on-Don, Russian Federation, nasledie don@mail.ru.

Vyacheslav P. Glebov, Candidate of Sciences (History), Researcher of Archaeological Research Bureau LLC, Ulyanovskaya St., 50, 344002 Rostov-on-Don, Russian Federation, glebov-63@mail.ru.

Vyacheslav N. Kuzmin, Staff Member of State Autonomous Institution of Culture of the Rostov Region "The Heritage of Don", Nizhnebulvarnaya St., 29, 344022 Rostov-on-Don, Russian Federation, nasledie_don@mail.ru.

\section{Информация об авторах}

Михаил Васильевич Власкин, директор ГАУК РО «Донское наследие», ул. Нижнебульварная, 29, 344022 г. Ростов-на-Дону, Российская Федерация, nasledie_don@mail.ru.

Вячеслав Петрович Глебов, кандидат исторических наук, научный сотрудник ООО «Археологическое научно-исследовательское бюро», ул. Ульяновская, 50, 344002 г. Ростов-на-Дону, Российская Федерация, glebov-63@mail.ru.

Вячеслав Николаевич Кузьмин, сотрудник ГАУК РО «Донское наследие», ул. Нижнебульварная, 29, 344022 г. Ростов-на-Дону, Российская Федерация, nasledie_don@mail.ru. 